\title{
Disposable Pipette Extraction Phase Based on Styrene-Divinylbenzene/ Pernigraniline Composite, Applied for Dexamethasone Determination in Synovial Fluid by HPLC with UV Detector
}

\author{
Francielle Q. Soares ${ }^{1}$, Bruna F. Alvarenga ${ }^{1}$, Marçal A. Ruggiero ${ }^{2}$, Monise C. Casanova ${ }^{1}$, \\ Eliana M. Lima ${ }^{3}$, Denilson Rabelo ${ }^{1}$ and Andréa R. Chaves ${ }^{1 *}$ \\ ${ }^{1}$ Instituto de Química, Universidade Federal de Goiás, Goiânia, Goiás, Brazil \\ ${ }^{2}$ Instituto Federal de Goiás, Inhumas, Goiás, Brazil \\ ${ }^{3}$ Faculdade de Farmácia, Universidade Federal de Goiás, Goiânia, Goiás, Brazil
}

Received: 08 March 2018; accepted: 22 June 2018

\begin{abstract}
A reliable method using disposable pipette extraction (DPX) based on composite of pernigraniline and styrenedivinylbenzene (Sty-DVB) copolymer was applied to the analysis of dexamethasone in synovial fluid using highperformance liquid chromatography and ultraviolet (UV) detector (HPLC-UV).

DPX variables, namely, number of draw/eject cycles for extraction or desorption, sample $\mathrm{pH}$, volume, and desorption solvent, were optimized to establish the best sorption equilibrium and analysis time. The highest extraction efficiency value was obtained with $50 \mu \mathrm{L}$ of synovial fluid mixed with $1950 \mu \mathrm{L}$ of water, in five cycles of $300 \mu \mathrm{L}$ of sampling, followed by liquid desorption of the drug with $300 \mu \mathrm{L}$ of methanol in three cycles. The developed method demonstrated a linear response over the range from 10 to $100 \mathrm{ng} / \mathrm{mL}$, with $R^{2}=0.993$. The limit of quantification (LOQ) was $10 \mathrm{ng} / \mathrm{mL}$. Based on the validation results, the proposed method can be a useful tool to detect dexamethasone levels in synovial fluid.
\end{abstract}

Keywords: Dexamethasone, DPX/HPLC-UV, synovial fluid, pernigraniline

\section{Introduction}

Dexamethasone is a corticosteroid drug that is usually involved with the proteins synthesis rate controlling.

Its main effect is the profound change made in lymphocyte immune response due to anti-inflammatory and immunosuppressive action also preventing or suppressing inflammatory processes of various natures. It is found in the pharmaceutical market as tablets, aerosol, creams, and ophthalmic suspensions [1]. Its empirical formula is $\mathrm{C}_{22} \mathrm{H}_{29} \mathrm{FO}_{5}$, and its structural formula is represented in Figure 1. It is rapidly absorbed after oral administration, and up to $65 \%$ of a dose is excreted in the urine within $24 \mathrm{~h}$. Its pharmaceutical effects strongly depend on its distribution in tissues and body fluids, such as synovial fluid. Synovial fluid is present in the synovial joints; it is a thick and stringy fluid, which reduces friction between articular cartilage and other tissues and joints, cushioning and lubricating them during the movements. For a better understanding of these effects, a detailed investigation of its pharmacokinetics is extremely necessary.

The most commonly used techniques for dexamethasone analysis have been liquid chromatography and spectrophotometric methods, as described in international official compendiums, depending on the pharmaceutical forms [2].

Liquid-liquid extraction (LLE) [2-5] and solid-phase extraction (SPE) $[6,7]$ are the most frequently sample preparation techniques used for drug extraction from biological fluids. These techniques are laborious and time consuming and require large amounts of organic solvents. The trends in analytical chemistry point toward methods that lead to simplification, miniaturization of analytical instrumentation and sample preparation techniques, and reduction of organic solvent and sample volumes [8].

*Author for correspondence: andrea_chaves@ufg.br; phone: 55-62 35211097.

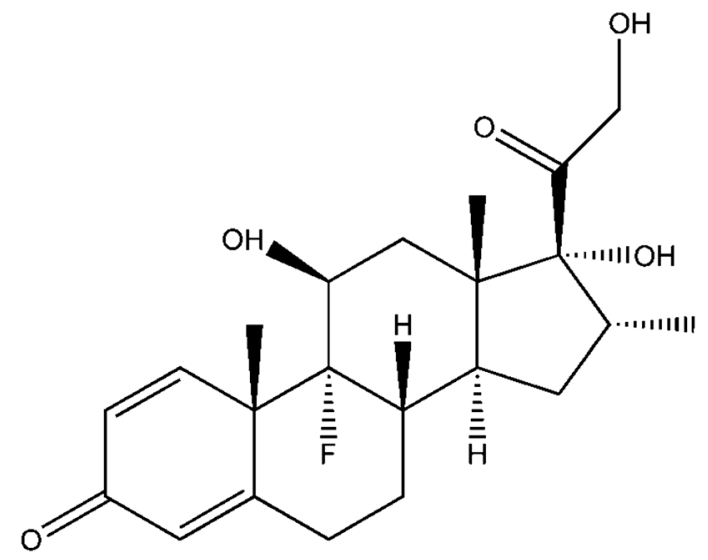

Figure 1. Structural representation of dexamethasone $\left(\mathrm{p} K_{\mathrm{a}}=12.4\right)$

A dispersive solid-phase micro extraction technique, known as disposable pipette extraction (DPX), relies on a disposable pipette tip with sorbent loosely contained inside of it, separated by a lower screen and upper barrier, enabling mixing the sorbent with sample solutions. One of its great advantages is that these tips do not require conditioning once the solution is mixed with the sorbent. In addition, channeling and flow rates have no impact on extraction efficiency for this type of dispersive solid-phase extraction technology.

DPX was developed as an alternative to traditional SPE, combining efficient and rapid extraction with significantly reduced solvent and time consumption. The extractions can be fully automated, thus reducing the risk of human error, improving repeatability, and increasing throughput $[9,10]$.

This is an open-access article distributed under the terms of the Creative Commons Attribution-NonCommercial 4.0 International License (https://creativecommons.org/licenses/by-nc/4.0/), which permits unrestricted use, distribution, and reproduction in any medium for non-commercial purposes, provided the original author and source are credited, a link to the CC License is provided, and changes - if any - are indicated. 
The first commercially available micropipette tip was based on chromatographic media, C18 microparticulates; since then, different phases with different interaction modes have been introduced $[11,12]$.

Recently our group presented a DPX extraction phase based on styrene-divinylbenzene (Sty-DVB) copolymer and polyaniline (PANI) composites, which was suitable for the antidepressants (fluoxetine and norfluoxetine) in plasma samples by highperformance liquid chromatography and fluorescence detection (HPLC-FD) [8]. The developed DPX method is shown to be very rapid, taking just a few minutes to perform without any solvent evaporation. However, higher standard deviation was observed between the developed phases suggesting poor chemical stability of the composites. To overcome this problem, StyDVB/PANI synthesis protocol has been improved.

In this paper, we describe a simple, sensitive, and reliable DPX/HPLC-UV method for the rapid determination of dexamethasone in a synovial fluid using a Sty-DVB/pernigraniline composite as the extraction phase. Polyaniline (PANI) can exist in three different redox forms, such as leucoemeraldine base (the most reduced form of PANI), emeraldine salt (the 50\% intrinsically oxidized form, in the salt form), and pernigraniline (the most oxidized form of PANI) [13].

\section{Experimental}

Chemicals and Samples. 1,4-Dioxane (UV/HPLC grade), benzoyl peroxide (BP) 65\%, acetone $99.5 \%$, aniline PA, and hydrochloric acid $37 \%$ were obtained from Vetec (Rio de Janeiro, Brazil). Toluene 99.5\% and heptane 98\% were obtained from LABIMPEX (São Paulo, Brazil). Methanol 99.8\%, ethanol $99.5 \%$, and gelatin powder were obtained from SYNTH (São Paulo, Brazil). The hydroxyethylcellulose (HEC) was acquired from Polithechno (São Paulo, Brazil), NaCl 99\% were obtained from ISOFAR (Rio de Janeiro, Brazil), styrene (Sty) was obtained from Lyondellbasell (Dallas, TX, EUA), and divinylbenzene (DVB), as a mixture of 50:50 $\mathrm{m}$ - and $p$-isomers, was purchased from PARCHEN (New York, U.S.A.), both were purified by reduced pressure distillation.

The dexamethasone analytical standards were donated by Lilly (São Paulo, Brazil). The working standard drug solutions were prepared by diluting the stock solutions of these drugs $(1 \mathrm{mg} / \mathrm{mL}$ in methanol) to a proper volume of methanol, based on their therapeutic intervals. These solutions were stable for 45 days at $-20{ }^{\circ} \mathrm{C}$. Water purified in a Milli-Q system (Millipore, São Paulo, Brazil) was used to prepare the mobile phase. Synovial fluids without dexamethasone, used as blank samples, were donated by the FarmaTec (Centro de Pesquisa, Desenvolvimento e Inovação Tecnológica em Fármacos, Medicamentos e Cosméticos) of Universidade Federal de Goiás. These studies were performed in accordance with the World Medical Association's "an Ethical principle for medical research involving human and animal's subjects". These synovial samples were spiked with target drug and used to optimize the DPX process and validate the analytical method.

Synthesis of Styrene-Divinylbenzene (Sty-DVB) Copolymer. Sty-DVB copolymer synthesis was carried out following the methodology described in a previous work [14]. Briefly, the aqueous phase (AP) was composed by HEC at $0.45 \%(w / v)$, $\mathrm{NaCl}$ at $0.60 \%(w / v)$, and gelatin at $0.12 \%(w / v)$. The organic phase (OP) was prepared dissolving $1 \%$ of initiator BP, Sty at $26 \%(v / v)$ and DVB at $84 \%(v / v)$ monomers. The porogenic agents were heptane and toluene in a volume ratio of $85 / 15$ and $150 \%$ dilution degree in relation to monomers volume. The ratio AP/OP was kept at 4:1 (v/v). The OP was added to the AP, the temperature was kept at $70{ }^{\circ} \mathrm{C}$ with stirring at $600 \mathrm{rpm}$ for $24 \mathrm{~h}$. Finally, the copolymer beads were filtrated and washed with water and then with ethanol to remove synthesis residues. The copolymer used to prepare the composite was sieved in the range of 53-75 $\mu \mathrm{m}$.

Synthesis of Sty-DVB Copolymer/Pernigraniline Composite. To Sty-DVB copolymer/pernigraniline composite synthesis, 1 gram of Sty-DVB copolymer was put in contact with $10 \mathrm{~mL}$ of acetone/aniline solution with a volume ratio of 20:80, and stirring for $3 \mathrm{~h}$. A reactive solution was prepared by mixing $0.14 \mathrm{~g}$ of $\mathrm{BP}$ in $5 \mathrm{~mL}$ of dioxane, $1.5 \mathrm{~mL}$ of water, and $1.25 \mathrm{~mL}$ of hydrochloric acid P.A. The swollen copolymer was filtrated and added to the reactive solution. The pernigraniline polymerization was carried out under stirring, at $25{ }^{\circ} \mathrm{C}$ for $24 \mathrm{~h}$. Afterwards, the composite was filtrated and washed with methanol and dried under ambient conditions. The complete procedure was repeated 4 times to ensure the maximum rate of reaction.

Physical-Chemical Characterization FTIR. Fourier transform infrared (FTIR) spectra were recorded using a Perkin Elmer Spectrum Frontier in the range of $4000-400 \mathrm{~cm}^{-1}$ for Sty-DVB copolymer and Sty-DVB/pernigraniline composite. Samples were analyzed using the attenuated total reflectance, ATR.

Scanning Electron Microscopy (SEM). Morfology of StyDVB/Pernigraniline composite was evaluated by SEM, in a Jeol JSM - 6610 Thermoscientific NSS Spectral Imaging (Peabody, MA, USA).

Nitrogen Adsorption Measurements. The specific surface area and pore size distribution measurements were performed using a Micrometrics ASAP 2010 nitrogen sorption porosimeter. Analysis was via nitrogen sorption carried out at $77 \mathrm{~K}$. Specific surface area was determined by BET method and the pore size distribution by the $\mathrm{BJH}$ method based on nitrogen desorption isotherm.

Chromatographic Conditions. The HPLC-UV analyses were performed on a Young-Ling, YL-9100 (Korea) chromatographic system equipped with a UV-diode array detector $(\lambda=205 \mathrm{~nm})$ and a HT800L autosampler (Gloucester, UK). The separation was performed in a Lichrosphere $60^{\circledR}$ RP: Select B $(250 \mathrm{~mm} \times 4 \mathrm{~mm}, 5 \mu \mathrm{m}$ particle size) (Merck, Darmstadt, Germany) column at temperature of $25{ }^{\circ} \mathrm{C}$; the chromatographic runs were performed in isocratic mode with a water-acetonitrile $(50: 50, v / v)$ mobile phase, at flow rate of $1.0 \mathrm{~mL} / \mathrm{min}$.

Optimization of DPX Process. DPX extraction was carried out in a pipette tip of $1 \mathrm{~mL}$, containing $50 \mathrm{mg}$ of Sty-DVB/ Pernigraniline composite. The sample consisted in a mixture of water/synovial fluid placed in a sample vial, in a ratio of $1950 \mu \mathrm{L}: 50 \mu \mathrm{L}$ water-synovial fluid. The synovial fluid was spiked with dexamethasone standard solution at therapeutic levels $(25 \mathrm{ng} / \mathrm{mL})$. To established the sorption equilibrium and shorten the analysis time, several parameters (number and volume of draw/eject sampling cycles, sample $\mathrm{pH}$, type, and volume of desorption solvent, and number of draw/eject desorption cycles) were optimized.

The influence of the sample $\mathrm{pH}$ on the extraction efficiency was evaluated at different $\mathrm{pH}$ values ranging from 4.0 to 8.0 ( $0.05 \mathrm{~mol} / \mathrm{L}$ buffer solutions). Different solvents (water, acetonitrile, methanol, water-methanol [50:50], and acetonitrile-water [50:50]). The used desorption solvent volume $(100-700 \mu \mathrm{L})$ was also evaluated to establish the desorption conditions. After the desorption process, the sorbent was washed with $500 \mu \mathrm{L}$ of water-methanol solution $(50: 50, v / v)$. The carryover was also evaluated.

Analytical Validation. In order to evaluate the linearity and all responses for the selected parameters, an analytical curve was constructed plotting the dexamethasone peak areas vs. concentration ( $\mathrm{ng} / \mathrm{mL}$ of dexamethasone in synovial fluid) and 
applying linear regression to it. Accuracy and inter-assay precision were determined by means of quintuplicate assays of the synovial fluid samples spiked with dexamethasone solution representing the entire range of the calibration curve. Accuracy values were calculated by the differences between concentrations of dexamethasone added to the synovial fluid samples and those obtained after extractions, by means of the analytical curve.

\section{Results}

DPX Extraction Phase Development. As mentioned on introduction section, the synthesis of Sty-DVB/PANI composite was based on our previously published work [8], however the developed composite in that case, did not exhibit adequate chemical stability and reproducibility between extractions cycles. In order to improve the extraction phase, the synthesis protocol has been modified resulting in the pernigraniline composite which has an over oxidation state. The morphology of synthesized Sty-DVB/pernigraniline composite was characterized by SEM. As shown in Figure 2, the composite exhibited a spherical and porous structure, of small particles which suggests high surface area and large extraction capacity. Such characteristic was confirmed by nitrogen adsorption analysis for Sty-DVB/pernigraniline composite, which showed a surface area of $323 \mathrm{~m}^{2} / \mathrm{g}$, a total pore volume of $1.34 \mathrm{~cm}^{3} / \mathrm{g}$, and an average pore diameter of $10 \mathrm{~nm}$.

Figure 3 shows the FTIR spectra for copolymer Sty-DVB and composite Sty-DVB/pernigraniline. The pernigraniline characteristic band located at $1488 \mathrm{~cm}^{-1}$ could be attributed to the stretching of the quinone (Q). The absence of $1556 \mathrm{~cm}^{-1}$ band, from benzenic (B) rings, is a property of pernigraniline [15], and the shoulder at $1630 \mathrm{~cm}^{-1}$ and the bands at 1445 , 1414 , and $1374 \mathrm{~cm}^{-1}$ are present in the spectra of the products obtained at low acidity. Other characteristic of pernigraniline could be attributed to the absence of band at $1310 \mathrm{~cm}^{-1}$, resulting from symmetrical stretching of $\mathrm{CN}$ groups of secondary aromatic amines. The band at $1159 \mathrm{~cm}^{-1}$ is attributed to the $\mathrm{CH}$ group, which is due to nitrogen linked to the quinone group $[15,16]$.

The extraction ability of pernigraniline could be attributed to the interactions between polymer and analyte, such as base-acid, dipole-dipole interactions, and hydrogen bonding, in addition to the $\pi-\pi$ and hydrophobic interactions. The increased affinity of pernigraniline and dexamethasone can be attributed to $\pi-\pi$ and hydrophobic interactions.

The physical and chemical stability of the composite has been investigated. The composite was subjected to a wide $\mathrm{pH}$ range (1 to 11$)$, salt concentrations $(\mathrm{NaCl}$ in $1 \%, 5 \%$, and $10 \% \mathrm{~m} / \mathrm{V}$ concentrations), and different solvents composition (methanol, water, acetonitrile, and mixtures of methanol-water [50:50, $v / v$ ]

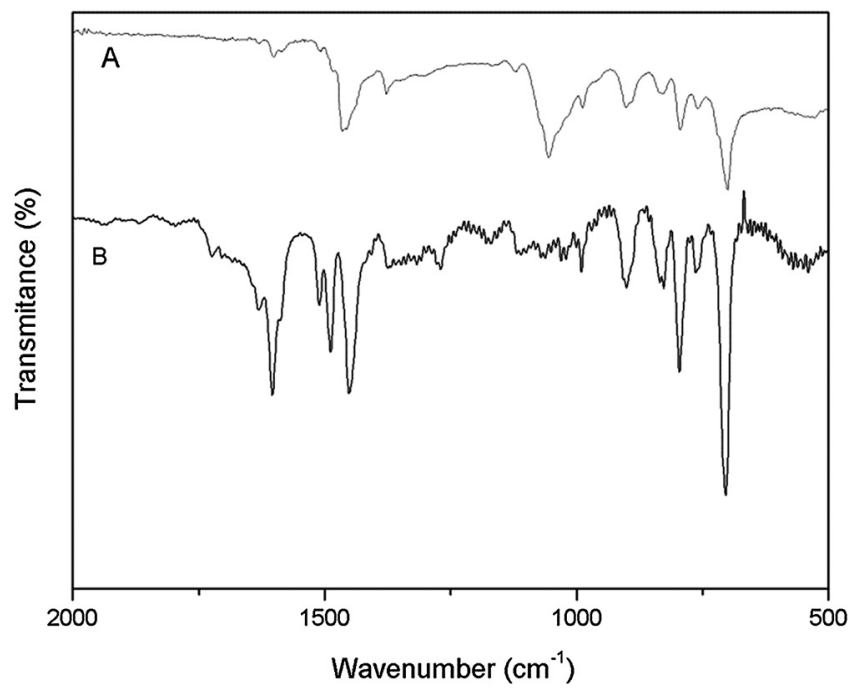

Figure 3. IR spectra of copolymer Sty-DVB (A) and composite Sty-DVB/Pernigraniline (B)

and acetonitrile-water [50:50,v/v]). The composite was stable for all investigated conditions. Comparing with commercial DPX phases (silica based), the Sty-DVB/pernigraniline was chemically stable at higher $\mathrm{pH}$ values such as 11.0 , while the silica derivate phases are damaged by strongly alkaline solutions $[10-12,17]$.

DPX Conditions Optimization. To reaching new extraction phases and methods, the sorption capacity, method sensitivity, and carryover are important parameters to be considered. Using the composite Sty-DVB/pernigraniline, and the DPX conditions were evaluated based on the extraction efficiency represented by chromatogram dexamethasone peak area.

The number of draw/eject cycles is a critical parameter for extraction recovery. The dexamethasone recovery rate increased above 1 extraction cycles $(1 \times 300 \mu \mathrm{L}$, Figure 4$)$. The extraction cycles were performed with the same aliquot, using five extraction cycles. This condition results in suitable limit of quantification (LOQ) value $(10 \mathrm{ng} / \mathrm{mL})$, precision (7.6 to $10.2 \%$ ), and accuracy ( 81 to $93 \%$ ) for dexamethasone at therapeutically levels. Therefore, this condition $(5 \times 300 \mu \mathrm{L})$, was performed in less than $30 \mathrm{~s}$, so it was used for subsequent experiments.

The sample $\mathrm{pH}$ was evaluated, and the obtained results suggested that in basic $\mathrm{pH}$ solutions, the electrostatic repulsion between analyte and pernigraniline coating was observed, which resulted in lower extraction efficiencies. Among the evaluated $\mathrm{pH}$ sample values, higher sensitivity of the DPX/ HPLC-UV method was obtained after the sample was diluted with $1950 \mu \mathrm{L}$ of water, in which the drug sorption into StyDVB/pernigraniline (Figure 5) had been favored.
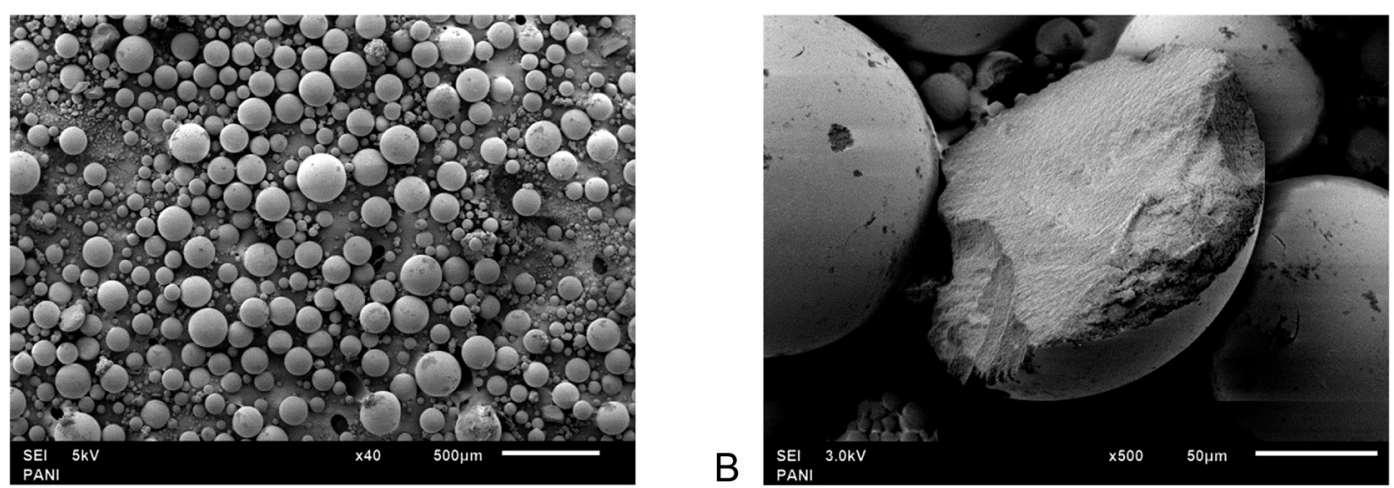

Figure 2. SEM micrographs of the Sty-DVB/Pernigraniline composite at 40-fold (A) and 500-fold (B) magnification 


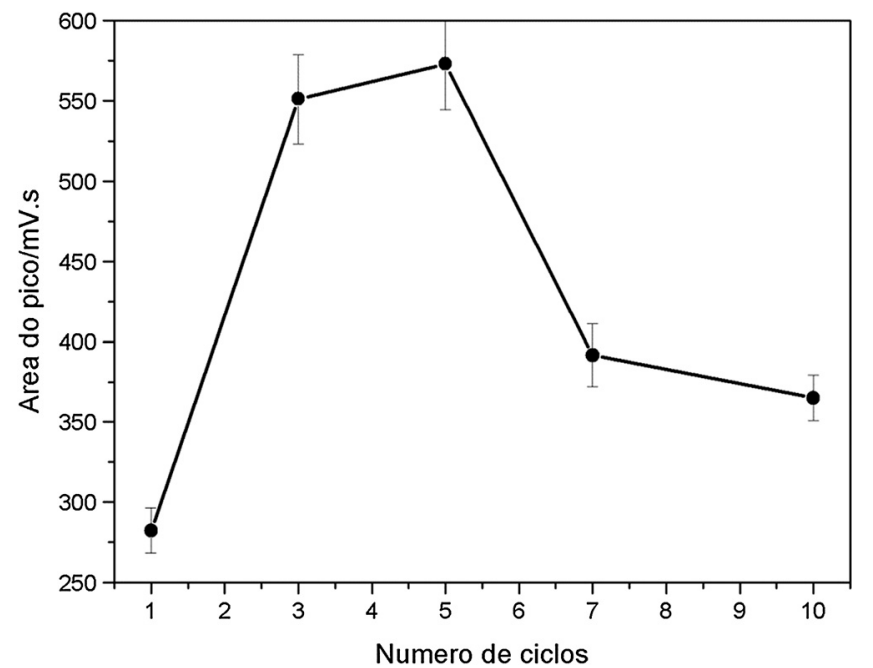

Figure 4. Effect of the number of DPX draw/eject extraction cycles over the extraction efficiency

Analyte was eluted by drawing/ejecting the solvent through the pipette tip. Methanol, water, acetonitrile, acetonitrile-water (50:50), and methanol-water (50:50) were evaluated as desorption solvents. Among these, methanol exhibited the highest desorption efficiency using three desorption cycles of $300 \mu \mathrm{L}$ for the same aliquot $(3 \times 300 \mu \mathrm{L})$ (Figure 6).

The extraction efficiency increased, comparing one to three draw/eject cycles $(300 \mu \mathrm{L})$, but above three cycles, the number of cycles did not substantially change the results (Figure 7). To improved recovery method values, methanol was drawn and remained in contact with the extraction phase for $10 \mathrm{~s}$ prior to being dispensed.

Between the extractions, the extraction phase was washed with methanol for 3 draw/eject cycles $(500 \mu \mathrm{L})$ to ensure that the matrix compounds were removed. A pipette tip containing the extraction phase was used over 20 times with water solutions without extraction efficiency decrease, and for the synovial fluid, each pipette tips was used 10 times with no extraction efficiency decrease was observed.

Based on these data, the best DPX experimental conditions among those investigated for dexamethasone assays (Figures 4-7) were $50 \mu \mathrm{L}$ of synovial fluid mixed with $1950 \mu \mathrm{L}$ of water, five extraction cycles $(5 \times 300 \mu \mathrm{L})$, followed by liquid desorption of the analyte with $300 \mu \mathrm{L}$ methanol in three desorption cycles.

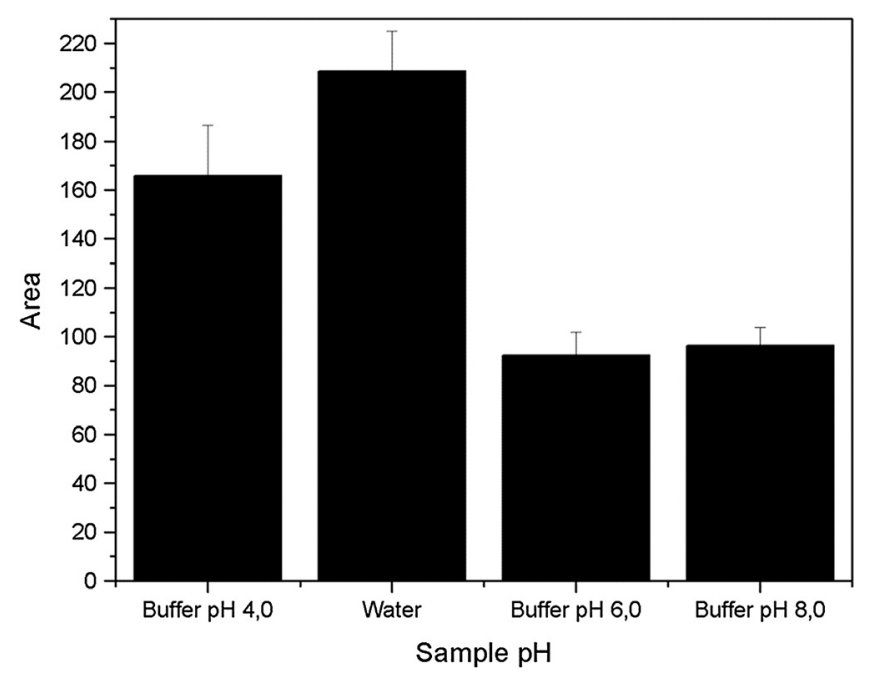

Figure 5. Effect of the sample pH over the DPX extraction efficiency

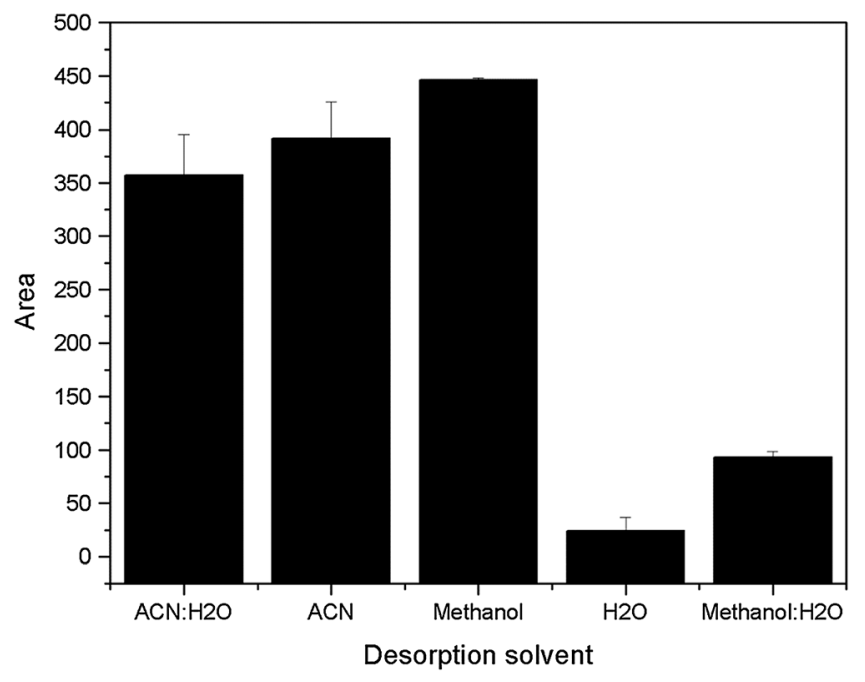

Figure 6. Effect of desorption solvent over DPX extraction efficiency

Analytical Validation. As shown in Figure 8A and B, the developed method was selective, once in the drug-free synovial fluid sample (Figure $8 \mathrm{~B}$ ), there is no significant signal comparing to the spiked sample (Figure 8A) with dexamethasone at the therapeutic concentration $(25 \mathrm{ng} / \mathrm{mL})$.

According to Figure 8, all those analytical signals relative to the possible interference at the same analyte retention time were lower than $20 \%$ of the chromatographic signal of the target drug at the concentration corresponding to the quantification limit concentration.

The linearity of the DPX/HPLC-UV method ranged from the LOQ of $10 \mathrm{ng} / \mathrm{mL}$ to $100 \mathrm{ng} / \mathrm{mL}$ for dexamethasone. The linear regression provided the equation $y=9.47 x+251.94$ with $R^{2}=$ 0.993 ( $x$ being the dexamethasone concentration, in $\mathrm{ng} / \mathrm{mL}$, and $Y$ represents the peak area obtained from chromatogram, in $\mathrm{mV} \mathrm{s})$. All points for analytical curve were performed in replicate $(n=5)$. The limit of quantification (LOQ) was attributed as the lowest concentration on the analytical curve for which the coefficient of variation (CV) was close to $10 \%$ (Table 1), based on a signal-to-noise ratio of 10 . The calculated LOQ was $10 \mathrm{ng} / \mathrm{mL}$.

The accuracy and inter-assay precision of the DPX/HPLC-UV method ( 5 replicates) were evaluated by using synovial fluid samples spiked with dexamethasone at different concentrations (Table 1). The method precision was calculated according to the

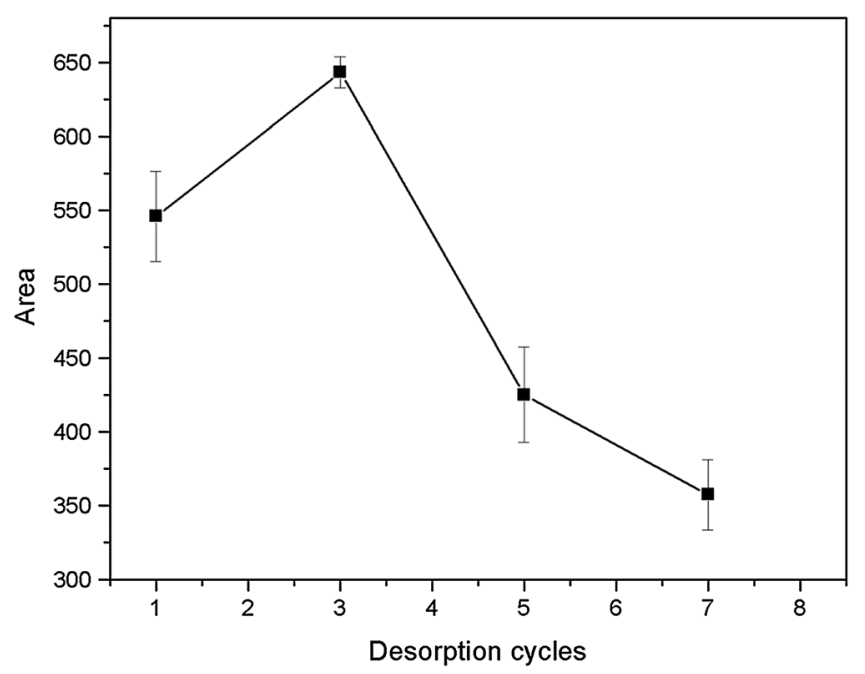

Figure 7. Effect of the number of draw/eject cycles of desorption solvent over the DPX extraction efficiency 


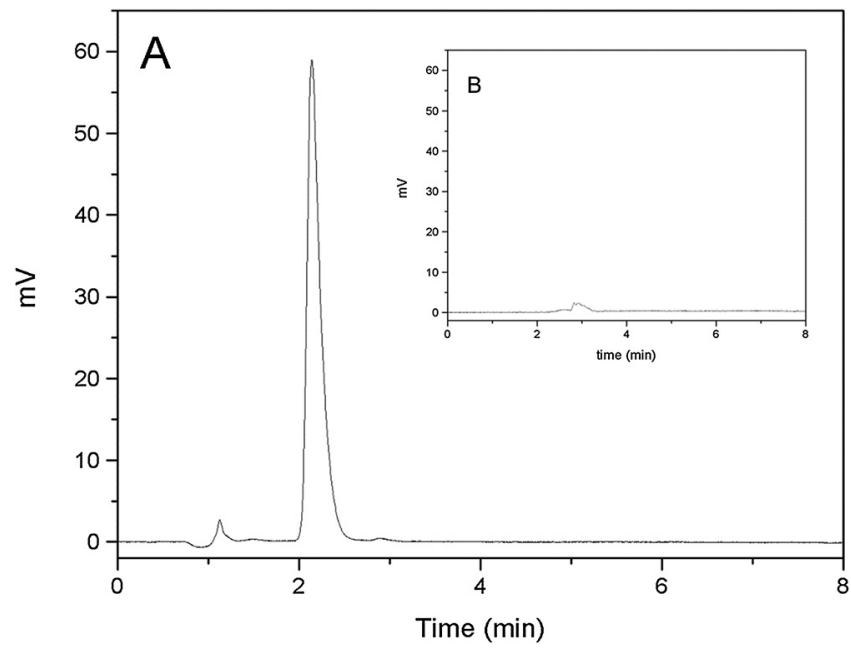

Figure 8. DPX/HPLC-UV chromatogram of: (A) synovial fluid spiked with dexamethasone $(25 \mathrm{ng} / \mathrm{mL})$ and $(\mathrm{B})$ blank sample of synovial fluid

Table 1. Inter-day precision (CV), accuracy, and recovery of DPX/HPLCUV method for dexamethasone in synovial fluid analysis

\begin{tabular}{lccc}
\hline Concentration $(\mathrm{ng} / \mathrm{mL})$ & CV $(\%)$ & Accuracy $(\%)$ & Recovery $(\%)$ \\
\hline 10 & 10.2 & 81 & 54 \\
25 & 9.8 & 85 & 69 \\
75 & 7.6 & 93 & 81 \\
\hline
\end{tabular}

CV\% (inter-assay) at three levels. The CV\% values ranged from $7.6 \%$ to $10.2 \%$ (Table 1 ), and the relative recovery was assessed via analysis of synovial fluid samples spiked with standards at the concentrations showed in Table 1. The recoveries were calculated by comparing the UV peak areas of the spiked samples with the peak area of the direct injection of dexamethasone solution at the same concentration, achieving values ranging from 54 to $81 \%$.

The complete DPX process described here, from the conditioning, sample loading, and elution, till washing steps, needed only $3 \mathrm{~min}$. This represents a huge reduction compared to traditional SPE methods, which can last for approximately $20 \mathrm{~min}$ [12]. The low synthesis cost, high recoveries, and the ability to reuse the same phase until 20 times without loss in efficiency are additional advantages to this new Sty-DVB/pernigraniline DPX extraction phase.

\section{Conclusion}

A new DPX extraction phase based on Sty-DVB/pernigraniline composite was successfully developed and applied to the analysis of dexamethasone in synovial fluid, showing good linearity and reproducibility under optimized conditions.

According to the miniaturization trends in analytical chemistry, the small volumes of synovial fluid and solvents, combined with reduced preparation time and cost, ensure that the presented work represents important advances not only to the sample preparation subject, but also for the environmental matter.

The method presented here represents a powerful tool for rapid, accurate, and quantitative determination of dexamethasone in clinical analyses.

Acknowledgements. Authors thanks Conselho Nacional de Desenvolvimento Científico e Tecnológico (CNPq) and Fundação de Apoio à Pesquisa do Estado de Goiás (Fapeg).

\section{References}

1. Martín-Sabroso, C.; Tavares-Fernandes, D. F.; Espada-García, J. I.; Torres-Suáreza, A. I. Int. J. Pharm. 2013, 458, 188-196.

2. Friedrich, R. B.; Ravanello, A.; Cichota, L. C.; Rolim, C. M. B.; Beck, R. C. R. Quim. Nova 2009, 32, 1052-1054.

3. Li, L.; Ma, P.; Wei, J.; Qian, K.; Tao, L. J. Chromatogr. B 2013, 933 , 44-49.

4. Patel, P.; Tanna, S.; Mulla, H.; Kairamkond, V.; Pandya, H.; Lawsona, G. J. Chromatogr. B 2010, 878, 3277-3282.

5. Yang, Y.; Li, H.; Gao, K.; Liu, M.; Sun, Y.; Yan, T.; Fawcett, J. P.; Cui, Y.; Gu, J. J. Chromatogr. B 2008, 862, 119-124.

6. Li, C.; Wu, Y.; Yang, T.; Zhang, Y. J. Chromatogr. A 2010, 1217, 411-414.

7. Ray, J. A.; Kushnir, M. M.; Rockwood, A. L.; Meikle, A. W. Clin. Chimi. Acta 2011, 412, 1221-1228.

8. Chaves, A. R.; Moura, B. H. F.; Caris, J. A.; Rabelo, D.; Queiroz, M. E. C. J. Chromatogr. A 2015, 1399, 1-7.

9. Lerch, O.; Vandenberg, J.; Albinus, T.; Tan, C. T.; Stanley, S.; Global analytical solutions - Gerstel AN/2012/11, 1.

10. Foster, F. D.; Cabrices, O. G.; Stuff, J. R.; Pfannkoch, E. A.; Brewer, W. E.; Global analytical solutions - Gerstel AN/2013/01, 7.

11. Hsieh, H. C.; Sheu, C.; Shi, F. K.; Li, D. T. J. Chromatogr. A 2007, 21, $128-135$.

12. Ota, S.; Miyazaki, S.; Matsuoka, H.; Morisato, K.; Shintani, Y.; Nakanishi, K. J. Biochem. Biophys. Meth. 2007, 70, 57-62.

13. Yoon, S.-B.; Yoon, E.-H.; Kim, K.-B. J. Power Sources 2011, 196, 10791-10797.

14. Moura, B. H. F.; Assis, R. H. B.; Franco, P. I. B. M.; Antoniosi Filho, N. R.; Rabelo, D. React. Funct. Polym. 2013, 73, 1255-1261.

15. Chowdhury, P.; Saha, B. Indian J. Chem. Technol. 2005, 12, 671-675.

16. Trchová, M.; Stejskal, J. Pure Appl. Chem. 2011, 83, 1803-1817.

17. Obaid, A. Y.; El-Mossalamy, E. H.; Al-Thabaiti, S. A.; El-Hallag, I. S.; Hermas, A. A.; Asiri, A. M. Int. J. Electrochem. Sci. 2014, 9, 1003-1015. 